\title{
0 protocolo e a precedência nas representaçóes ritualizadas do Presidente da República francesa - De uma forma de comunicação política a uma representação simbólica do poder*
}

\section{RESUMO}

O autor postula que, nas práticas do poder, desde os tempos da corte, o protocolo e a precedência acompanham a lenta modificação das sensibilidades. Elaboramse novas relações entre os homens com novas regras de comportamento. Para ele, pode-se considerar que as práticas representativas e ritualizadas do poder são ao mesmo tempo projeção e espelho. Projeção de valores e de normas de um poder visível que mascara sua força e sua violência sob os códigos das representações. Espelho porque representações do poder são uma espécie de referência reflexiva de práticas similares (idéia de paradigma institucional).

\section{PALAVRAS-CHAVE}

imaginário

política

sociedade

\section{ABSTRACT}

The author thinks that, in the practices of the power, the protocol and the precedence accompany the slow modification of the sensibilities and of the western man's behaviors. New relationships are elaborated among the men with the establishment of new rules and forms of behavior. For him, it can be considered that the representative practices are at the same time projection and mirror. Projection of values and norms of a visible power under the codes of the representations. And mirror because the representations are a type of reflexive reference of similar practices (idea of institutional paradigm).

\section{KEY WORDS}

imaginary

politics

society
A título de introdução, convém, em primeiro lugar, tentar dar uma impressão precisa quanto ao contexto histórico e sociológico do nosso tema. Neste sentido, é possível se basear nos trabalhos de Norbert Elias (1985b) sobre a "sociedade da corte". Sem entrar na exegese de suas pesquisas, o aspecto mais importante diz respeito à idéia de uma consumação de prestígio indexada diretamente no extrato social. Na verdade, a sociedade "da corte", para Elias, pode ser interpretada de duas maneiras. De um lado, no sentido de uma sociedade dotada de uma "corte", ou seja, o conjunto dos empregados domésticos como serviçais diretos do Rei, incluindo os nobres que o servem. Esta corte é organizada como a propriedade pessoal do Rei. De outro lado, entende-se a corte como sendo uma sociedade inteira à parte, um verdadeiro instrumento de "formação social". O extrato, isto é, o fato de pertencer e de ocupar um lugar hierárquico junto à nobreza, implica, pois, uma obrigação social de representar e de se colocar em representação.

Concretamente, pode-se falar de um verdadeiro estilo de vida. A casa do aristocrata deve refletir sua posição social e a necessária razão de obrigação de representação. Assim, pode-se distinguir o apartamento onde se recebem as visitas oficiais. Por causa da separação do espaço conforme o sexo, os esposos habitam, cada um deles, um quarto, e vivem separadamente. Ainda mais genericamente, a casa dos nobres deve, imperativamente, ultrapassar em arquitetura, em luxo, em refinamento e em decoração à dos burgueses, mesmo sendo mais ricos. A conseqüência direta desta estilização da relação social é que o aristocrata deve efetuar suas despesas de acordo com sua classe social, o que o conduz a ter certo desprezo em relação ao dinheiro e a suas contingências econômicas. Por outro lado, o burguês é cuidadoso em manter suas despesas inferiores às receitas. O que acontece é o desenvolvimento de um "sistema de despesas" (Elias) que impõe despesas de prestígio ligadas à obrigação de representar valores e normas sociais das quais não se pode escapar.

É preciso acrescentar, também, que a consumação de prestígio indexada diretamente ao extrato social é, evidentemente, sustentada pela posição que se ocupa na ordem nobiliárquica (barão, visconde, conde, marquês, etc.). O que importa é o prestígio e não a riqueza. A classe nobiliárquica determina o nível das obrigações de representação a satisfazer e, ao mesmo 
tempo, introduz um funcionamento concorrencial feito de competições, de rivalidades, de ciúmes. É preciso guardar sua posição. A sociedade da corte é uma sociedade feita de tensões sociais exploradas e instrumentalizadas pelo Rei, que continua sendo o centro do sistema.

Para além dessa "consumação de prestígio" ligada ao extrato social, existe um segundo ponto importante a considerar: como a "sociedade da corte" prefigura a invenção do homem moderno? A resposta a esta questão se encontra parcialmente contida no que Norbert Elias chama "étiquette". A etiqueta é um conjunto de convenções e de regras que fundamenta cada detalhe da vida cotidiana. Na verdade, o Rei vive em um espaço impenetrável e inigualável, o castelo de Versalhes. Neste lugar, se estendem e se amplificam as práticas sociais "etiquetadas" que definem uma atitude, uma função, um lugar a cada um dos atores da corte. Com isso, as práticas sociais "etiquetadas" se encontram na vida cotidiana de Versalhes. É, por exemplo, o fato de se assistir, sob algumas condições, o coroamento do Rei (o "pequeno" ou o "grande coroamento"), o almoço ou a janta, a hora de dormir ou a de vestir uma camisa. Os gestos do cotidiano mais banal se acham erigidos à altura de um quase ritual. Luís XIV instaura, pois, um jogo instável e flutuante, sobre o qual ele reina com maestria. Ele é o organizador de um ritual centrado na sua pessoa.

Esta noção de etiqueta constitui um dos quadros de referência do que acontece hoje com a maioria das regras de civilidade e, mais particularmente ainda, das regras do protocolo e da precedência. A partir desta concepção normatizada da vida social sob a forma de uma representação permanente é possível atualizar as características funcionais particulares, que não são muito distantes das do protocolo e da precedência. Isto é tão mais verdadeiro que a etiqueta permite mostrar sua classe e seu poder através das representações de prestígio. Oferece imensos privilégios para alguns e não para outros em uma sociedade de Direito. Permite, ainda, guardar a distância entre o Rei e os outros nobres (sem confusão ou comparação possível). Permite manter as camadas sociais distintas (evitar casamentos com pessoa considerada de casta inferior). E, enfim, permite o crer no ver ${ }^{1}$.

Neste sistema de tensões sociais, de rivalidades de status, o homem da corte deve, pois, necessariamente cultivar algumas qualidades, como a arte de observar seus semelhantes e de observar a si mesmo, a fim de dissimular suas paixões e sentimentos ${ }^{2}$. Norbert Elias fala de «autoconstrangimentos». Mas o Rei também é engajado no sistema de etiqueta e, para bem governar, deve governar a si mesmo. Assim se manifesta o que Norbert Elias chama o "processo de civilização". A sociedade da corte é uma escola que visa a disciplinar os comportamentos sociais e a controlar seus efeitos. Ela é o crisol da fábrica do homem moderno. Pode- se, então, sustentar a idéia que a "racionalidade pontifícia" está na origem das regras de civilidade e de "politesse". É um sistema no qual cada um depende do outro e todo o indivíduo depende do Rei. Elias fala de "interdependências" 3 . Na verdade, não existe verdadeira separação entre a vida pública do Rei e sua vida privada. A ação do Estado é uma ação pessoal. Este último ponto é essencial, pois marca a grande diferença com a época contemporânea: uma certa "despersonalização" da ação política.

\section{As representaçóes do poder na França}

A partir deste contexto histórico e social, é possível abordar a questão do protocolo e da precedência nas representações ritualizadas do presidente da República francesa. O homem político contemporâneo é um ser civilizado, que reprime suas pulsões. O processo de "curialização" se transformou em uma espécie de hábito psíquico, através do qual o homem público adapta seus gestos, controla sua aparência, cuida das suas expressões. Tudo está dentro do "distanciamento" das relações (Elias), em relação aos outros, mas também em relação a si mesmo.

\section{De uma parte, porque o poder político deve se inserir em todas as dimensões do social, e, de outra parte, porque o que domina nas nossas sociedades é a invasão dos suportes midiáticos (a televisão e a internet).}

Assim, o que caracteriza a superfície das representações do poder na França é uma impressão de forma lisa, de forma conveniente e também de conveniências (no sentido de "formas exteriores"). As representações do poder não são mais confinadas apenas no espaço do Palais (palácio) ou na doce economia de uma "sociedade da corte". Por duas razões essenciais. De uma parte, porque o poder político deve se inserir em todas as dimensões do social, e, de outra parte, porque o que domina nas nossas sociedades é a invasão dos suportes midiáticos (a televisão e a internet).

A realidade desta constataçãoé que as representações do presidente da República francesa, como expressão de seu poder, se manifestam em todas as atividades, das mais simples e cotidianas até as mais diretamente ligadas aos exercício de seu estatuto de presidente. Todas as atividades presidenciais estruturam as 
"configurações", no sentido com que Georg Simmel entende esse termo, ou seja, como percepções interdependentes de função e de relações sociais (Simmel, 1981, 1998; Elias, 1970).

Sob a forma de uma espécie de inventário "à la" Prévert, não deixa de ser interessante enunciar todas as atividades do presidente da República francesa:

O presidente chega. Ele participa da campanha eleitoral. Ele se elege. O poder é transmitido do antigo para o novo presidente em uma cerimônia. O presidente se vai. Ele deixa o poder de maneira institucional ou ele morre durante o mandato.

O presidente preside. Ele participa de diferentes tipos de reunião, de conselhos, de comitês e conferências nacionais.

O presidente comemora. Todos os anos (8 de maio de 1945, 18 de junho de 1940, 14 de julho, 11 de novembro de 1918) ou ainda periodicamente (centenário, bicentenário).

O presidente assiste. Ele assiste eventos militares, manifestações e finais esportivas, manifestações culturais, concertos, exposições, peças teatrais.

O presidente recebe. Ele oferece recepções oficiais (as visitas de Estado, as visitas oficiais, as visitas privadas) e particulares, audiências, encontros e entrevistas protocolares, consultas, almoços ou jantares, presentes ${ }^{4}$.

O presidente viaja. Pela França ou ao exterior, de modo oficial, privado ou inopinado.

O presidente se exprime. Sob a forma de pronunciamentos, discursos, entrevistas, conversas, coletivas de imprensa, mensagens à Nação, apresentação de votos ${ }^{5}$.

De modo geral, pode-se já reparar que estas representações desenvolvem a expressão de uma vontade de ocupar sistematicamente todos os aspectos das práticas sociais. Existe uma espécie de "disseminação" destas práticas em todos os interstícios do social: receber, trocar (no sentido amplo) viajar, celebrar, comemorar, inaugurar, decorar, exprimir, etc. Para tentar apresentar e compreender a função social das representações do poder, é preciso lembrar que o conjunto das ações presidenciais, que são enumeradas, se acha no quadro codificado do protocolo e da precedência. É preciso observar, também, que $\mathrm{o}$ protocolo e a precedência constituem apenas elementos e codificações de uma possível partitura das representações políticas. Trata-se, de qualquer forma, de uma hipótese. As diferentes disposições impostas pelas regras protocolares servem, como as notas, para colocá-las na música, e de suporte.

\section{A tradição do protocolo e da precedência na França}

Para compreender esta tradição é desejável desenvolver duas dimensões que definem os contornos políticos do protocolo e da precedência na França: uma dimensão funcional e uma dimensão estrutural. É preciso, pois, dar uma definição mínima e geral do que constitui o protocolo. As regras do protocolo e da precedência são, antes de tudo, modos de ser que se podem definir da seguinte maneira ${ }^{6}$ : um modo de repartição dos corpos, no espaço e no tempo; um dispositivo que contribui para destacar o poder político; um fixador de hierarquia por regras de correção bem precisas, e enfim, um redutor de formas de representação que poderiam ser aleatórias ou arbitrárias. De certa forma, o protocolo ordena, classifica, divide, hierarquiza, agrega, institui.

\section{A função social e política do protocolo e da precedência}

$\mathrm{O}$ protocolo e a precedência são, acima de tudo, modos de ser, repartição dos corpos, cena do poder político e administrativo, hierarquização, divisão, classificação, agregação, institucionalização, e, pois, ocupa um lugar central na concepção e expressão de todas as atividades do presidente da República. Através do protocolo e da precedência, o presidente pode se impor tanto real quanto simbolicamente, sem que por isso suas prescrições sejam, em si mesmas, as representações específicas. É importante, pois, não confundir o que se trata do código (as regras) do que é relevante na própria representação (a cerimônia). Isso quer dizer que as representações do poder político devam ser consideradas como formas de relações sociais à parte, constituídas a partir de fatores como: a classificação protocolar das autoridades, a posição hierárquica (grade, título, etc.), a função (chefe, diretor, etc.). As formas destas relações sociais determinam a deferência, o respeito, a submissão.

O protocolo é uma estrutura viva, mesmo se as disposições pareçam congeladas. Esta codificação minuciosa e estrita mostra a importância dada ao fato de estabelecer ou de manter as relações pacíficas entre os homens. De que serve o protocolo? Para permanecer no quadro estrito das representações do poder, enquanto atividades significantes, pode-se dizer que o uso do protocolo e da precedência contribui a iluminar e reforçar as relações sociais entre os indivíduos e seu estatuto no interior dessa relação. De outra forma ainda e mais detalhadamente, podemos destacar os quatro efeitos principais do protocolo: sobre os atores, sobre os espectadores, sobre a "figura objetiva" do estrangeiro, sobre os símbolos em geral.

\section{Efeitos sobre os atores}

Reforçam os valores e as normas sociais em função de uma ordem e de uma hierarquia necessárias; determina as posições individuais em uma ordem espacial: ser estático, estar em pé, estar sentado, estar separado, estar perto: determina as ações individuais em momentos considerados fortes como uma chegada (ou entrada), um deslocamento, uma partida (uma saída); enfim, determina comportamentos específicos, principalmente de respeito, obediência e submissão. 


\section{Efeitos sobre os espectadores}

O protocolo evidencia, de modo concreto, as regras sociais convencionais como regras de polidez ou deferência; reforça as convicções ao legitimar a autoridade presidencial; provoca e canaliza as emoções através do rigor das encenações.

\section{Efeitos sobre uma "figura objetiva" 7 do estrangeiro}

O protocolo, a partir das visitas de hóspedes estrangeiros (ou visitas oficiais de personalidades francesas), permite o reconhecimento exato de seus estatutos, dissipando, assim, toda ambigüidade. Permite, também, nos encontros de personalidades da mesma camada social, marcar esta igualdade.

\section{Efeito sobre os símbolos em geral}

O protocolo retifica as distorções simbólicas; evita os conflitos simbólicos; fornece a imagem reflexa do poder em termos de hierarquia, de especialização, de centralização.

As conseqüências diretas destes quatro efeitos do protocolo são que a afirmação política do presidente da República pelas representações de poder está diretamente ligada à expressão de seu poder, poder considerado ao mesmo tempo como capacidade de fazer e como capacidade de se fazer obedecer. Para ir mais longe, o presidente se legitima na eleição, ato pelo qual os indivíduos de uma mesma comunidade são, em parte, despossuídos de sua própria capacidade nestes domínios. Através do voto e da eleição do presidente da República como única figura do poder, a comunidade nacional realiza uma transferência de capacidade: o presidente encarna a Nação. Assim, cada disposição protocolar lembra o conjunto da comunidade nacional de que o lugar proeminente ocupado pelo presidente é, na verdade, aquele da Nação inteira, e que, nessa identificação, reside, de um lado, o princípio da legitimidade presidencial.

\section{As finalidades estruturais do protocolo e da precedência nas representações do poder}

De uma maneira rápida, pode-se dizer que as regras protocolares se organizam em torno de quatro eixos principais. Estes correspondem a finalidades estruturais particulares em termos de formação da representação: marcar a ruptura com o regime anterior; ratificar a hierarquia e uma autoridade; e, enfim, instituir e modelar as práticas políticas.

\section{Estabelecer uma ruptura ou uma transição com o regime}

É preciso compreender, aqui, as noções de "ruptura" e de "regime", recobrindo os momentos de transição, de passagem, introduzindo mudanças tanto reais quanto simbólicas na natureza dos poderes políticos. Por exemplo, a passagem da Monarquia à República, a mudança da maioridade com a chegada da Esquerda em 1981, o retorno da Direita em 1995 e em 2002, ou ainda, os períodos de "coabitação" (1986, 1993, 1997). Esta "ruptura" (transição) é sempre efetuada relativamente a um regime percebido ou apresentado como "antigo".

De modo geral, a ruptura com um determinado regime se assemelha à função coercitiva das representações presidenciais pelo seu uso simbólico da força e da encenação desta que passa a deter a força (o novo mestre). Cada vez que o poder se afirma em uma situação de ruptura, seja de forma brutal (revolução) ou alternativa (troca de maioria), o poder deve, obrigatória e ostensivamente, apresentar uma nova face, a partir, porém, do que seja preciso manter de semelhança com o velho regime para que também seja marcada a continuidade do poder. É raro se falar de ruptura total. Logo, o protocolo e a precedência asseguram, por um lado, esta "continuidade da mudança".

$\mathrm{O}$ uso das representações políticas inscrito em um imperativo protocolar aparece como o elemento motor que permite alcançar uma parte do mecanismo de reconhecimento social e de institucionalização política no momento das responsabilidades do poder. Mas, de maneira geral, é também a possibilidade de lutar contra uma desagregação do poder quando este é, de uma maneira ou de outra, ameaçado ${ }^{8}$. As representações do poder podem ser também a afirmação de uma certa fragilidade.

\section{Definir um estatuto único para cada ator (subentendido com as prerrogativas particulares ligadas ao estatuto do presidente da República)}

A Constituição da $5^{a}$ República na França dá ao presidente da República um quadro estatutário que define sua posição em relação à lei. Mas, em uma perspectiva dinâmica, isto é, uma perspectiva tendo em conta as representações codificadas do presidente, interessa substituir este estatuto rígido do presidente no quadro das condutas sociais. O que significa dizer, de modo concreto, que podemos descrever três estatutos presidenciais elementares: 1) conjunto de direitos e deveres (Constituição, protocolo, precedência, hábitos, etc.); 2) segundo critérios de sexo, de idade, de posição social e política. ${ }^{9}$, e 3 ) as modalidades de expressão próprias ao sistema social de referência, e é o que nos interessa mais. Ou seja, de acordo com sua posição hierárquica, ela mesma variável segundo o poder supremo (manifestações de caráter nacional) ou situada entre seus pares (encontros protocolares entre chefes de Estado).

Assim, as representações do poder codificadas pelas regras do protocolo e da precedência podem, através da repetição e encenação regulares, preencher as funções de expressão ou de reforço (do estatuto) social presidencial. Em outros termos, o presidente dispõe de uma margem de manobra quanto à encenação de seus estatutos e uma utilização orientada das regras 
protocolares.

\section{Ratificar uma autoridade}

As representações do poder presidencial servem para afirmar a autoridade do poder. As circunstâncias nas quais esta afirmação acontece podem responder a um princípio de novidade, após a chegada de um novo presidente (De Gaulle de 58, Mitterrand de 81), seja ainda a um princípio de reiteração, a fim de assinalar a permanência deste poder. Não seria exagero falar aqui do rito e dos rituais. Mas se poderia levar em conta unicamente uma dimensão de comunicação: ratificar a autoridade. Sendo assim, na perspectiva em que nos situamos, as representações do poder não podem ser consideradas como atos de comunicação estrita, na medida em que o que está em jogo se articula com objetos (objetivos) de natureza e finalidade diferentes.

$\mathrm{Na}$ verdade, de maneira não exaustiva e para ilustrar a pluralidade de representações presidenciais, convém sublinhar alguns aspectos no domínio da comunicação como, por exemplo, o fato de construir uma "forma histórica de legitimidade"; de construir, também, "uma figura do eleito" ideal ${ }^{10}$, de realizar "a síntese simbólica da ordem e do poder" ou, ainda, de realizar, através dos indivíduos, o enunciado potencial (na medida em que ela não realiza de forma obrigatória) de normas sociais em vista de sua integração à sociedade (estes dois aspectos se encontram em Rivière, 1995a).

De fato, existe uma dimensão comunicacional, mas nem mais nem menos do que as dimensões ideológicas, instrumentais e funcionais. A confusão vem do fato de que as representações políticas ao ratificarem uma autoridade oferecem, em geral, uma percepção "naturalizante" das relações sociais. Quanto mais a aparência parece "natural", maior é a eficácia das distinções sociais e as finalidades diversificadas (eficácia do poder).

\section{Idealizar um modelo de práticas políticas}

As representações do poder podem ser consideradas como a projeção ideal de um modelo de práticas políticas. Encontra-se esta particularidade em dois planos distintos. De um lado, o plano de colocar uma codificação geral por ranqueamento protocolar e de precedência por cerimônias oficiais, que se destinam a todas as autoridades civis ou militares estando em obrigações oficiais. Em seguida, o plano das práticas efetivas das representações políticas, a fim de revelar similitudes. Esta situação pode ser imputada ao reforço das regras existentes anteriormente (são, por exemplo, as reformas das regras do protocolo e da precedência em 1989 e 1995).

Podemos, assim, reter três modos de adaptação ou de apropriação das representações do poder por outros tipos de autoridade: seja por décalage protocolaire (decalagem protocolar), e o melhor exemploé dado pelo Primeiro Ministro, que participa das representações da mesma natureza que as do presidente da República; seja por similitude fonctionnelle (similitude funcional), quando o presidente da República preside uma cerimônia como as do 8 de Maio ou de 11 de novembro. Em praticamente cada comuna da França se desenrola uma cerimônia (quase idêntica), presidida pelo prefeito ou pelo governador; seja, enfim, por appropriation symbolique (apropriação simbólica), quando há a propriação de cerimônias (ou de símbolos) por grupos ou organizações camponesas ${ }^{11}$.

\section{Conclusão}

O uso e a utilidade históricos do protocolo e da precedência são, paradoxalmente, duplos. Eles fundam e ratificam uma distinção, aquela que separa o homem de poder daquele que não o detém. Mas o protocolo e a precedência, preservando a especificidade minoritária de um estilo de vida (aquele do presidente da República), são, também, o ponto de onde se transmitem as novas condutas, que vão se estender às outras camadas da sociedade.

Assim,oprotocoloea precedênciaacompanhamalenta modificação das sensibilidades e dos comportamentos do homem ocidental. Progressivamente, elaboram-se novas relações entre os homens ao se instaurarem novas regras e formas de comportamento, como o controle de si e a observação do outro, além da regulação de uma economia pulsional. Podemos considerar que as práticas representativas e ritualizadas do poder são ao mesmo tempo projeção e espelho. Projeção de valores e de normas de um poder visível que mascara sua força e sua violência sob os códigos das representações. Espelho na medida em que as representações do poder são uma espécie de referência reflexiva, de ponto de iniciação de práticas similares (idéia de paradigma institucional). Basta que para isso observemos as práticas representativas do conjunto do corpo político e administrativo (Governo - Primeiro Ministro, eleitos, deputados, prefeitos, governadores). Enfim, pode-se dizer que o poder avança sempre mascarado, dando a sua mensagem as aparências de uma hierofania (uma aparição sagrada) —FAMEcos

\section{NOTAS}

* Tradução: Eduardo Portanova Barros. Bolsista CNPq-Brasil

1 "Para crer, ele [o povo] precisa ver". ELIAS, Norbert. La société de cour. Paris: Champs Flammarion, 1985.

2 Por exemplo, os duelos passam a ser substituídos pela oratória. Esta prática é ilustrada no filme Ridicule, de Patrice Leconte (1996). Convém ver também o filme de Sofia Coppola, Marie Antoinette (2006). Neste filme, mostra-se a troca real e simbólica do estatuto de Marie-Antoinette, o peso do protocolo, da precedência e da etiqueta. 
3 É uma noção que ele explica utilizando a metáfora do jogo de xadrez: "Como no jogo de xadrez, toda ação de relativa independência representa um lance no tabuleiro social que provoca, infalivelmente, um contragolpe de um outro indivíduo (sobre o tabuleiro social, trata-se, na realidade, de muitos contragolpes executados por muitos indivíduos) limitando a liberdade de ação do primeiro jogador". ELIAS, Norbert. La société de cour. Paris: Champs Flammarion, 1985, p.152-153.

4 Concretamente, são as recepções oficiais de hóspedes estrangeiros, as recepções privadas, a arte do café da manhã, os jantares e aniversário, os almoços de reconciliação, as recepções institucionais, as audiências e encontros protocolares, a audiência de um novo eleito à Academia Francesa, as consultas, as recepções particulares, a árvore de Noel do Elysée, etc.

5 Concretamente, são também as mensagens presidenciais oficiais (às assembléias, à Nação, às Forças Armadas, à imprensa, etc.)

6 “O protocolo é (...) uma ordem, um modo de repartição dos corpos, um dispositivo que contribui para encenar o poder político. O historiador, o político, o antropólogo, o jurista podem, a seu respeito, encontrar questões fundamentais. O protocolo classifica, divide, hierarquiza". DÉLOYE, Y.; HAROCHE, C. \& IHL O. Le protocole ou la mise en forme de l'ordre politique. Paris: L'Harmattan, 1996, p. 15.

7 "Figura objetiva", no sentido de intervenção e construção social.

8 Claude Rivière resume perfeitemente estes mecanismos quando um sistema político reage à ameaça de sua integridade (eu cito Claude Rivière): "Plus un régime ressent la fragilité en son intérieur et l'insécurité en ses entours plus il se barde d'interdits, plus il énonce cérémoniellement ses principes et codes d'action, plus il réclame des citoyens des signes extérieurs, répétitifs, ritualisés, d'allégeance, et d'intégration sociale". RIVIÈRE, Claude. Les rites profanes. Paris: PUF, 1995, p. 60. "Quanto maior a fragilidade e a insegurança do regime em seu interior, mais interdições e enunciados de seus princípios e códigos de ação ritualizados de integração social".

9 No atual estágio das nossas práticas sociais, é, na verdade, esperar que uma mulher ou uma pessoa de menos de 40 anos possa exercer as funções de presidente da República. Existe na França uma espécie de "androcentrismo".
10 Estes dois aspectos são desenvolvidos por ABÉLÈS, Marc. Anthropologie de l'etat. Paris: Armand Colin, 1990.

11 Por exemplo, estes tipos de situação são verificados nas cerimônias do 14 de julho, do 11 de novembro ou na festa de Jeanne d'Arc, através da utilização de elementos simbólicos presentes nas representações presidenciais. Sobre esse ponto específico, ver: FLEURDOGE, Denis. La circulation des symboles dans les rituels et les représentations du politique. Usages, détournement, appropriation. Symboles et symbolismes. In: Les cahiers de l'Imaginaire, Montpellier: Presses Universitaires de la Méditerranée, Ed. 22, p.29-40, 2007.

\section{REFERÊNCIAS}

ABÉLÈS, Marc. Anthropologie de l'etat. Paris: Armand Colin, 1990.

DELOYE, Y.; HAROCHE, C. , \& IHL, O. Le protocole ou la mise en forme de l'ordre politique. Paris: L'Harmattan, 1996.

ELIAS, Norbert. La civilisation des meurs. Paris: Agora, 1985.

La société de cour. Paris: Champs Flammarion, 1985.

Qu'est-ce que la sociologie? Paris: Editions de l'Aube, 1970.

FLEURDOGE, Denis. La circulation des symboles dans les rituels et les représentations du politique. Usages, détournement, appropriation. Symboles et symbolismes. In: Les cahiers de l'Imaginaire, Montpellier: Presses Universitaires de la Méditerranée, Ed. 22, p.29-40, 2007.

RIVIÈRE, Claude. Les liturgies politiques. Paris: PUF, 1995.

Les rites profanes. Paris: PUF, 1995.

SIMMEL, Georg. Sociologie et épistémologie. Paris: PUF, 1981

Sociologie. Paris: PUF, 1998. 